\title{
Recognition of script-typical versus script-atypical information: Effects of cognitive elaboration
}

\author{
EDGAR ERDFELDER and JÜRGEN BREDENKAMP \\ University of Bonn, Bonn, Germany
}

\begin{abstract}
Memory for script-atypical information has been shown to be superior to memory for script-typical information. Two explanations of this typicality effect are evaluated: (1) the attention-elaboration hypothesis (AEH) and (2) the script-copy-plus-tag hypothesis (SCTH). The AEH claims that atypical information is recognized better because it attracts more attention and cognitive elaboration. According to the SCTH, memory representations of script-based texts are established automatically and constitute a copy of the script plus tags for atypical events that facilitate later recognition. We investigated recognition memory and memory for the presentation form of typical and atypical items originally shown with versus without missing letters. Experiment 1 showed that presenting items in fragmentary form tends to improve recognition memory mostly for highly typical items. Experiment 2 revealed that the size of this missing-letters effect is affected by the presentation form of items preceding the target items during acquisition. For fragmented items preceded by other fragmented items, the typicality effect virtually disappeared. Memory for the presentation form of items was generally moderate. These results are readily explained within the AEH framework and pose some problems for the SCTH.
\end{abstract}

Research on schema-based information processing has repeatedly shown that recognition of verbal information that fits well into an event schema or script is inferior to recognition of atypical information. For instance, if individuals read a story entitled "Peter's Visit to a Restaurant" and subsequently respond to an unexpected recognition test, they are better at discriminating old from new sentences if these sentences state atypical actions (e.g., "Peter removes a hair from the soup") as opposed to sentences describing highly typical actions (e.g., "Peter paid the bill"). This so-called typicality effect has been observed both in adults (Bellezza \& Bower, 1981; Bower, Black, \& Turner, 1979; Davidson, 1994; Graesser, Gordon, \& Sawyer, 1979; Graesser, Woll, Kowalski, \& Smith, 1980; Maki, 1990; Markham \& Lissner, 1994; Smith \& Graesser, 1981; Yekovich \& Walker, 1986; for reviews, see Graesser \& Nakamura, 1982, and Mandler, 1984) and in young children (Adams \& Worden, 1986; Davidson \& Hoe, 1993; Hudson, 1988). Moreover, similar effects have been reported with respect to face recognition (e.g., Light, Kayra-

The authors thank Natascha Braun, Arndt Bröder, Ralf Dehondt, Peter Esser, Frank Fischer, Ulrike Gleißner, Britta Hofmann, Thomas Krüger, and Alf Müller for their aid in story construction, programming, data collection, and coding. They are also indebted to Ute J. Bayen. Axel Buchner, Klaus Fiedler, Arthur C. Graesser, Christoph Klauer, and Patricia Tenpenny for many helpful remarks on previous versions of this paper. The work on this article was supported by grants of the Deutsche Forschungsgemeinschaft (DFG) to J.B. (Br301/6-1, $\mathrm{Br} 301 / 6-2$, and $\mathrm{Br} 301 / 6-3$ ). Correspondence should be addressed to E. Erdfelder or J. Bredenkamp, Psychologisches Institut der Universität Bonn, Römerstr. 164, D-53117 Bonn, Germany (e-mail: erdfelder@ uni-bonn.de or juergen.bredenkamp(auni-bonn.de).

—Accepted by previous associate editor Kathryn T. Spoehr
Stuart, \& Hollander, 1979; Locksley, Stangor, Hepburn, Grosovsky, \& Hochstrasser, 1984; for a review, see Shapiro \& Penrod, 1986), the recognition of scenes (Fabricius, Hodge, \& Quinan, 1993; Friedman, 1979; Mäntylä \& Bäckman, 1992; Pezdek, Whetstone, Reynolds, Askari, \& Dougherty, 1989), natural situations (Nakamura, Graesser, Zimmerman, \& Riha, 1985), persuasive messages (D. F. Schmidt \& Sherman, 1984), and person attributes (e.g., Locksley et al., 1984; Woll \& Graesser, 1982; see Stangor \& McMillan, 1992, for a review).

Still, there appear to be some exceptions to this rule (see Mandler, 1984, p. 106; Stangor \& McMillan, 1992). However, a closer look at these studies reveals that the deviating results were due to either methodological or conceptual shortcomings: In some cases, recognition hit rates were not properly corrected for response bias (e.g., Brewer \& Treyens, 1981; Cantor \& Mischel, 1977; C. E. Cohen, 1981); in other cases typicality was confused with relevancethat is, the degree of relatedness of information to a schema or script (see Mandler, 1984, pp. 101-108). Although the effect of schema relevance on bias-corrected measures of recognition memory is not so clear-cut (Brewer \& Nakamura, 1984; Davidson, 1994; Maki, 1990; McDaniel \& Kerwin, 1987), the effect of schema expectancy (or schema consistency) definitely is. In the present paper, the term script-atypical information refers only to unexpected information-that is, information that is relevant to the script but has a low a priori probability of occurring when the script is activated. Analogously, script-typical information is defined as script-relevant information that is frequently associated with the script.

Many theories of schema-based information processing predict superior recognition memory for atypical information (see Graesser \& Nakamura, 1982, for a re- 
view), but not all of them offer unique explanations. Up to now, only two clearly distinguishable explanations of the typicality effect have been proposed in the literature (see Stangor \& McMillan, 1992, who express a similar point of view). Some theorists either explicitly or implicitly refer to the concept of levels of processing (Craik \& Lockhart, 1972), according to which the depth of cognitive processing determines how well information can be retrieved. Because unexpected events attract more attention and encourage greater effort in elaborative processing than typical events, they are presumably processed more deeply. Hence, it should be easier to retrieve them. This explanation is widely known as the attentionelaboration hypothesis (AEH) and often attributed to Bobrow and Norman (1975). Similar explanations are offered by other theorists of schema-based information processing (e.g., Bower et al., 1979; Hastie, 1980).

A second class of schema theories denies the importance of attention and elaborative processes. Instead, they emphasize the principle of cognitive economy, according to which a piece of information will not be transmitted to long-term memory if it is implied by general knowledge. Thus, atypical and moderately typical, but not highly typical, actions need to be stored because the latter are implied by the script (Schank \& Abelson, 1977). A prominent example of this class of theoretical conceptions is the script-copy-plus-tag hypothesis (SCTH; Graesser \& Nakamura, 1982). The SCTH claims that during the course of script comprehension, a memory representation is established automatically that essentially consists of two parts: (1) a copy of the script, including its highly typical actions, regardless of whether they have actually been displayed or not, and (2) a set of tags depicting additional information that is atypical or, at best, moderately typical of the script. Because of these tags, it should be easy subsequently to recognize atypical and some of the moderately typical actions. In contrast, most of the typical and all highly typical actions and events are part of the memory representation by default - that is, even if they were not stated explicitly. Therefore, it should be difficult and sometimes even impossible to discriminate highly typical actions that were actually read or heard from those that were not. Note that attentional and elaborative processes are completely irrelevant according to this theoretical account. Hence, such processes must not affect the size of the typicality effect.

The SCTH not only explains the typicality effect but also predicts a number of other well-established results of schema and script research (see, e.g., Bredenkamp \& Vaterrodt, 1992; Graesser \& Nakamura, 1982; GrubeUnglaub, Bredenkamp, Vaterrodt-Plünnecke, \& Fischer, 1995). We will consider some of these results in the discussion section of this paper and focus on the different explanations of typicality effects here. Our goal was to test both explanations simultaneously by studying the impact of a treatment that presumably leads to a higher level of attention and cognitive elaboration during encoding. A suitable candidate for such a treatment is the presentation form of items. Consider, for example, the sentence "Peter is looking for an empty table." This sentence can be displayed in fragmentary form as follows: "Peter is lo.k. .g for an empty table." Actually, this way of presenting information is a variant of the so-called generate condition (Slamecka \& Graf, 1978). Superior memory performance for information encoded under generate conditions as opposed to read conditions is well established for many measures of memory and several experimental designs (see, e.g., Burns, 1990). This generation effect has been attributed to an increase in elaborative semantic encoding (Graf, 1982), conceptually driven processes (Blaxton, 1989; Roediger, Weldon, \& Challis, 1989), and the mobilization of attentional and other cognitive resources during information generation (Fiedler, Lachnit, Fay, \& Krug, 1992; S. R. Schmidt, 1992). Measures of memory correlating positively with these types of processing (e.g., recall and recognition) tend to show strong generation effects, whereas measures that are more strongly linked to data-driven processes (e.g., most indirect measures of memory) are associated with null or even negative generation effects (Blaxton, 1989).

$\mathrm{McDaniel}$, Einstein, and collaborators explored the effect of a letter-deletion variant of the generate condition that is similar to the fragmentary presentation condition investigated in the present article (e.g., Einstein, McDaniel, Bowers, \& Stevens, 1984; Einstein, McDaniel, Owen, \& Coté, 1990; McDaniel, 1984; McDaniel, Einstein, Dunay, \& Cobb, 1986; McDaniel \& Kerwin, 1987). Their results confirm the prediction that missing letters may enhance item-specific and proposition-specific processing during encoding. Missing letters contribute to superior memory performance to the degree that (1) they induce intense elaborative processing of the target items, (2) the memory test performance benefits from elaborative item-specific processing during encoding, and (3) itemspecific processing is not already implied by other context conditions or by the stimulus material itself (which would render the missing-letters effect redundant). McDaniel et al. (1986), for instance, found a positive effect of missing letters on recall of a fairy tale (presumed normally to invite schema-based relational processing during encoding), whereas the same treatment did not affect recall of a descriptive text (presumed normally to lead to intense item-specific processing during encoding). With respect to recognition memory, McDaniel and Kerwin $(1987$, p. 249) observed that missing letters enhance recognition for all types of information except "important" (i.e., particularly salient) information.

Taken together, these studies suggest that missing letters can effectively enhance elaborative, item-specific processing, provided that intense item-specific processing is not already implied by other aspects of the experimental setting. This helps in deriving predictions from the $\mathrm{AEH}$ and the SCTH referring to memory tasks in which both recognition and source discrimination of scriptbased information are required from the participants. More specifically, assume that items of information vary- 
ing in typicality are presented in either complete or fragmentary form in one text. Subsequently, following a distractor activity, participants are confronted with an unexpected source monitoring task (see Johnson, Hashtroudi, $\&$ Lindsay, 1993, for a review). They are asked to classify old and new test items as old and originally presented in complete form (old $\left.\mathrm{c}_{\mathrm{c}}\right)$, old and originally presented in fragmentary form $\left(\right.$ old $\left._{\mathrm{f}}\right)$, or new. This task allows one to assess both recognition memory and source memory for script-typical versus script-atypical information. In this application, source memory refers to discriminating between past item presentation forms.

According to the AEH, the typicality effect is caused by enhanced elaborative processing of atypical information. If atypical information indeed receives higher levels of item-specific processing by default, then the extra processing implied by missing letters is likely to be rather ineffective. As a consequence, the missing-letters effect on recognition memory must be quite small or even absent for atypical information. Recognition of highly typical information, by contrast, may benefit from itemspecific processing induced by missing letters because low levels of attention and cognitive elaboration are directed toward these items when presented in complete form. The size of this missing-letters effect should largely depend on the degree of elaborative processing implied by the missing letters, which in turn may depend on the attentional resources allocated to the letter-completion task (e.g., because of its difficulty). Given sufficient attentional resources, the missing-letters effect should be larger for highly typical items than for atypical items. As a consequence, the typicality effect for items originally displayed in complete form (henceforth referred to as "complete items") must exceed the typicality effect for items originally displayed in fragmentary form (henceforth referred to as "fragmented items").

With respect to source memory, the level of itemspecific processing induced by missing letters is relevant for deriving predictions. According to the $\mathrm{AEH}$, the extra processing of both atypical and fragmented items is semantic in nature, at least under incidental learning conditions where participants do not expect a subsequent source monitoring test referring to the item presentation form. Whereas memory for the item content will probably benefit from additional semantic processing, memory for surface characteristics such as the item presentation form is not likely to be affected. Therefore, source memory should be relatively constant across item types and presentation forms. More specifically, source memory is likely to be moderate or poor for all items because memory for surface information vanishes rather quickly when attention is directed toward semantic aspects of texts (see, e.g., Alba \& Hasher, 1983; Kintsch \& Ericsson, 1996; Kintsch, Welsch, Schmalhofer, \& Zimny, 1990; Schmalhofer \& Glavanov, 1986).

In deriving predictions from the $\mathrm{SCTH}$, two possible interpretations of this hypothesis need to be distinguished. Proponents of a narrow version of the SCTH could argue that highly typical items have no representation in memory beyond the copy of the script, regardless of their presentation form. From this perspective, of course, the missingletters effect must be nonexistent for highly typical items, and bias-corrected recognition probabilities should be very low. Moreover, memory for the presentation form of highly typical items must also be very poor. No unique predictions can be derived with respect to recognition memory and source memory for atypical items; for these items, there may or may not be a missing-letters effect.

In contrast, advocates of an extended version of the SCTH could allow for "extra tags" indicating unusual presentation forms or other nonstandard attributes of an item. The memory representation of fragmented items, therefore, would comprise the script copy, perhaps tags for moderately typical or atypical information, and an extra tag for coding that this information was constructed from an incomplete sentence. This latter kind of tag, if still available at test, should help subsequently to discriminate the item from new items. Put another way, complete items should be harder to distinguish from new items because their memory representation lacks extra tags. Hence, recognition memory must be enhanced for fragmented items as compared with complete items, and this should hold true for highly typical, typical, and atypical items to similar degrees. In contrast, source memory must not differ between item presentation forms because extra tags should improve source memory for all types of items to the same amount. This prediction derives from the fact that source memory refers to those items only that are already recognized as old. Obviously, if a fragmented item is recognized as old, the extra tag reveals that the item must have been presented in fragmentary form originally. Similarly, if a complete item is recognized as old, the missing extra tag suggests that the original information was displayed in complete form. Thus, very good source memory should emerge in any case, regardless of typicality.

To summarize, the AEH predicts a relatively strong missing-letters effect on recognition memory for highly typical information and a weak or null effect for atypical information. As a consequence, the typicality effect should be weaker for fragmented as opposed to complete items. The SCTH predicts either a null effect of missing letters in highly typical items (narrow version of the SCTH) or an additive effect with approximately equal recognition memory benefits for highly typical, typical, and atypical information, leaving the magnitude of the typicality effect unchanged (extended version of the SCTH). Graesser and Nakamura $(1982$, p. 86) prefer this second version of the SCTH over the first one: "For the most part, the representational code and the typicality effect do not depend on the encoding strategies and the goals of the comprehender during comprehension. The magnitude of the typicality effect should remain essentially constant across different encoding contexts."1

The AEH and the SCTH also differ in their predictions concerning source memory: Memory for the presentation form of an item should be moderate or poor accord- 
ing to the AEH and either very poor (narrow version) or very good (extended version) according to the different SCTH versions. These predictions refer to all levels of typicality and to both forms of item presentation.

Obviously, empirical tests of all these predictions presuppose valid measures of recognition memory and source memory. However, the validity of currently available empirical measures of item recognition and source discrimination in source monitoring tasks has been seriously questioned by Batchelder and Riefer (1990) and Murnane and Bayen (1996). These authors showed that under some conditions at least all available empirical measures of source memory confound memory for the item with memory for the source; that is, they may indicate differences in source memory when there are in fact no such differences, but only differences in recognition memory. Even more importantly, none of the empirical measures proves to be unaffected by response biases. This holds true even if $d^{\prime}$ is used as a measure of recognition memory in source monitoring tasks. Collapsing the old and old $_{\mathrm{f}}$ responses into a single old category and calculating $d^{\prime}$ estimates from the hit and false alarm rates may result in biased measures of recognition memory (for details see Batchelder, Riefer, \& Hu, 1994; Thomas \& Olzak, 1992, pp. 263-264). This is a serious drawback, especially in schema and script research, because item typicality affects both memory processes and judgment processes in case of recognition uncertainty (see Alba \& Hasher, 1983, p. 224; Locksley et al., 1984). In fact, the SCTH predicts a larger response bias toward old responses for highly typical items as opposed to atypical items: Because highly typical items are part of the memory representation by default, it should not only be difficult to discriminate between old and new highly typical items but also reasonable to guess old in most of these cases. In contrast, because atypical items are probably new unless tagged within memory, a tendency to guess new must be expected for those atypical items that cannot be recognized as old. Obviously, if response bias toward old responses actually increases with script typicality, measures of recognition memory that are contaminated with this bias can obscure or perhaps even invert the typicality effect in recognition memory as predicted by both the $\mathrm{AEH}$ and the SCTH.

For these reasons, a model-based approach is desirable that accounts for simultaneous effects of recognition memory, source memory, and response biases on source monitoring data. Model-based approaches essentially have two advantages: First, they provide parameters that can be regarded as unconfounded, pure measures of recognition memory, source memory, and response biases, given that the assumptions underlying the model are valid. Second, the validity of the assumptions underlying the model can largely be assessed empirically. In the area of source monitoring research, Batchelder and Riefer (1990) were the first to propose such an approach. However, their multinomial processing-tree model of source monitoring is based on a one-high threshold (1HT) model of item recognition that is known to be a poor model for simple yesno recognition tasks (e.g., Kintsch, 1970). Batchelder and Riefer's (1990) model has therefore been criticized (Kinchla, 1994). Although the inadequacy of the 1HT assumption for yes-no recognition tasks does not necessarily imply its inadequacy as part of a one-high threshold source monitoring (1HTSM) model (Batchelder, Riefer, \& Hu, 1994), alternative multinomial models of source monitoring have been proposed in response to Kinchla's criticism (Batchelder, Hu, \& Riefer, 1994; Batchelder, Riefer, \& Hu, 1994; Bayen, Murnane, \& Erdfelder, 1996; Riefer, $\mathrm{Hu}, \&$ Batchelder, 1994). Recently, Bayen et al. (1996) compared these models empirically and found a twohigh threshold source monitoring (2HTSM) model to be superior to the other models: The item recognition and source discrimination parameters of the 2HTSM model accurately reflected independent experimental manipulations of recognition and source memory, whereas the corresponding parameters of other models failed to reflect manipulations of recognition memory.

The results of the Bayen et al. (1996) study are but one reason why we prefer the 2 HTSM model as a framework for the data analyses reported in this paper. Another reason is conceptual in nature: The 2HTSM model allows for (some) distractor items to be detected as new with certainty (i.e., without guessing). Currently, this feature is unique to the 2HTSM model. It is especially attractive in schema and script research because probably quite a few atypical distractor items are detected as new with certainty. When confronted with atypical distractor items in the memory task, participants could reason that they would have recognized this salient item as old had it been presented during the acquisition phase of the experiment. Since they do not recognize the item, it must certainly be new (see Strack \& Bless, 1994).

The application of the 2HTSM model to the source monitoring task used in our experiments is illustrated in Figure 1. The model comprises eight free parameters in its most general form. These parameters represent recognition memory $\left(D_{\mathrm{f}}, D_{\mathrm{c}}, D_{\mathrm{n}}\right)$, source memory $\left(d_{\mathrm{f}}, d_{\mathrm{c}}\right)$, response bias with respect to the old-new decision $(b)$, and response bias with respect to the source decision $(a, g)$. The model applies to fragmented items, complete items, and distractor items. The uppermost of the three processing trees in Figure 1 illustrates memory and judgment processes involved in responding to fragmented items. According to the 2HTSM model, fragmented items are recognized as old with probability $D_{\mathrm{f}}$. Given that a fragmented item is correctly recognized as old, the source of the item (i.e., the original presentation form) is correctly remembered with probability $d_{\mathrm{f}}$. If a fragmented item is both recognized as old and identified as originally presented in fragmentary form, the participant will correctly respond old . However, if a participant is unable to 

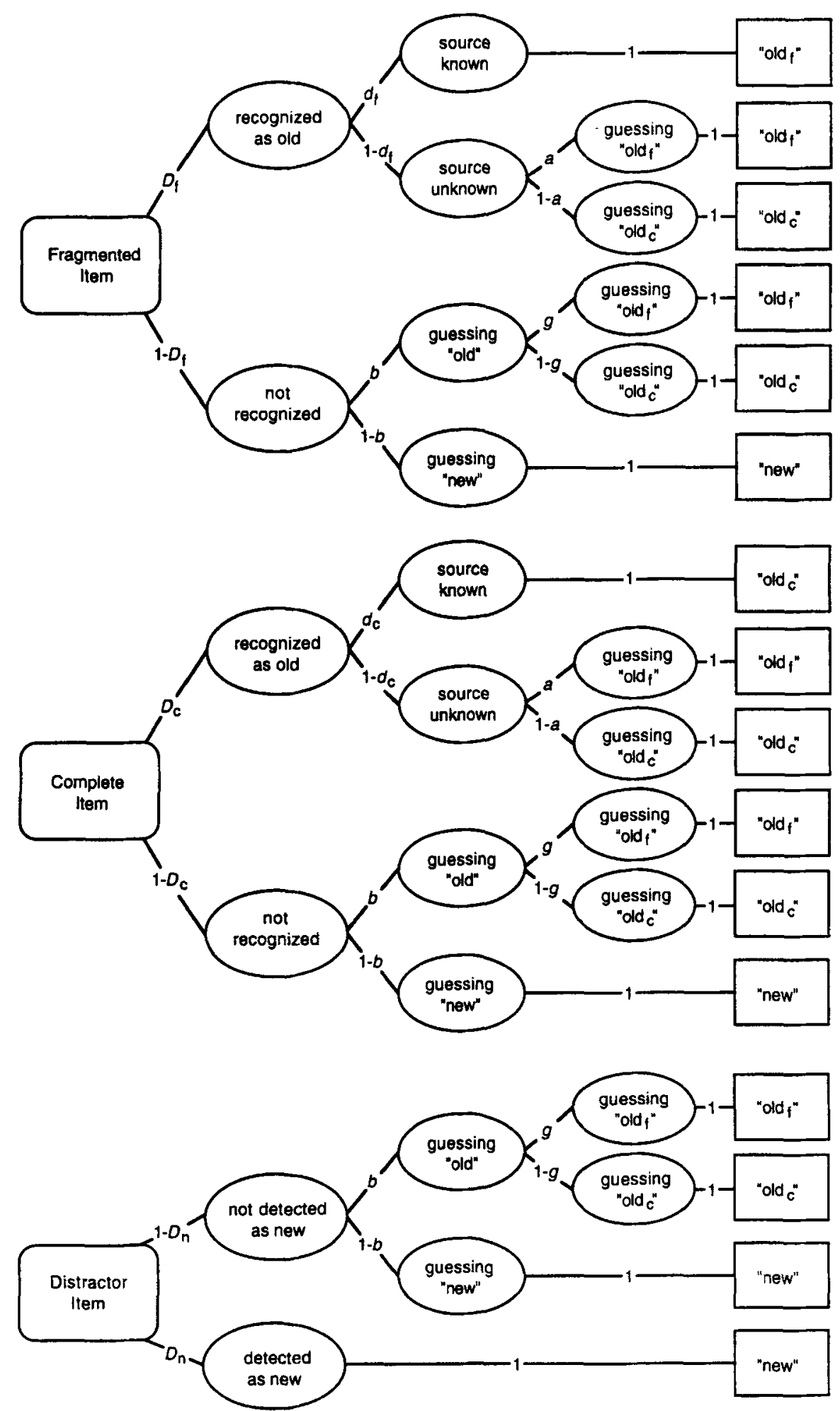

Figure 1. Processing-tree representation of the two-high threshold source monitoring (2HTSM) model applied to items originally presented in fragmentary versus complete form and distractor items. Words depicted in boxes denote test items (left side) and observable responses (right side). Events depicted in ellipses denote results of various memory and judgment processes involved in responding to the items. Italicized letters attached to the branches represent event transition probabilities from left to right. From "Source Discrimination, Item Detection, and Multinomial Models of Source Monitoring," by U. J. Bayen, K. Murnane, \& E. Erdfelder, 1996, Journal of Experimental Psychology: Learning, Memory, \& Cognition, 22, p. 202. Copyright 1996 by the American Psychological Association. Adapted with permission. 
remember the source conditional upon recognizing the item (with probability $1-d_{\mathrm{f}}$ ), this person will guess old $d_{\mathrm{f}}$ with probability $a$ and $o l d_{\mathrm{c}}$ with probability $1-a$.

By implication, fragmented items will fail to be recognized as old with probability $1-D_{\mathrm{f}}$. If this occurs, both the old-new decision and the source decision are made by guessing. The parameter $b$ is the probability of guessing old in the state of recognition uncertainty, and $g$ denotes the probability of guessing old $_{f}$ given that the old decision was also made by guessing. In principle, $g$ and $a$ may differ. However, it is often reasonable to assume that $g=a$ (i.e., source bias does not depend on recognition memory).

The processing tree for complete items (second tree in Figure 1) is completely isomorphic to the processing tree for fragmented items, except that the recognition probability $\left(D_{\mathrm{c}}\right)$ and the source discrimination probability $\left(d_{\mathrm{c}}\right)$ may differ from $D_{\mathrm{f}}$ and $d_{\mathrm{f}}$, respectively.

A slightly different model is proposed for distractor items (third tree in Figure 1). Distractor items are detected as new with probability $D_{\mathrm{n}}$, followed by a correct rejection (new response). If distractor items fail to be detected as new (with probability $1-D_{n}$ ), the same guessing processes as in case of target items apply.

In essence, the only difference between this 2HTSM model and the 1HTSM model by Batchelder and Riefer (1990) pertains to the $D_{\mathrm{n}}$ parameter. The 1HTSM model is a submodel of the 2HTSM model that is obtained by fixing $D_{\mathrm{n}}$ at zero. Thus, results of data analyses based on the 1HTSM and 2HTSM models will differ to the degree that $D_{\mathrm{n}}$ differs from zero.

In their most general versions, none of the source monitoring models proposed in the literature is identifiable; that is, at least some of the models' parameters are not uniquely determined by the response probabilities. This also holds true for the eight-parameter 2HTSM model depicted in Figure 1. Therefore, parameter restrictions are necessary in order to guarantee unique parameter estimates. A reasonable starting point in identifying an appropriate submodel is the most parsimonious submodel of the 2HTSM model family, namely the 2HTSM(4) submodel, comprising only four parameters $D, d, b$, and $g$. In this submodel, the parameters $D_{\mathrm{f}}, D_{\mathrm{c}}$, and $D_{\mathrm{n}}$ are replaced by a single recognition memory parameter $D$. Analogously, $d_{\mathrm{f}}$ and $d_{\mathrm{c}}$ are replaced by a single source memory parameter $d$. Finally, $g$ is assumed to be equal to $a$. This model was evaluated by Bayen et al. (1996) and was found superior to alternative four-parameter models derived from other model families. Obviously, most of its equality restraints are in agreement with the predictions derived from the $\mathrm{AEH}$ and the SCTH. In fact, according to the narrow version of the SCTH, all restrictions implied by the $2 \mathrm{HTSM}(4)$ model should hold true for highly typical items at least, and both $D$ and $d$ should be close to zero for highly typical items. However, the extended version of the SCTH and the AEH predict superior recognition memory for highly typical items originally presented in fragmentary form (i.e., $D_{\mathrm{f}}>D_{\mathrm{c}}$ ). According to this prediction, a five-parameter $2 \mathrm{HTSM}(5)$ model that leaves $D_{\mathrm{f}}$ unrestricted but retains the other restraints (i.e., $D_{\mathrm{c}}=D_{\mathrm{n}}$, $d_{\mathrm{f}}=d_{\mathrm{c}}$, and $g=a$ ) should do better than the $2 \operatorname{HTSM}(4)$ model. Therefore, by comparing the goodness of fit of the $2 \mathrm{HTSM}(4)$ and $2 \mathrm{HTSM}(5)$ models, the narrow version of the SCTH can be tested against the other hypotheses. If the 2HTSM(5) model proves to be clearly better for highly typical items, the narrow version of the SCTH must be rejected. In this case, the AEH and the extended version of the SCTH can be evaluated by comparing the typicality effects in $D_{\mathrm{f}}$ and $D_{\mathrm{c}}$ and by estimating the value of $d$ that should be moderate or poor according to the AEH and almost perfect according to the SCTH version assuming extra tags.

We applied this evaluation strategy to two source monitoring experiments that fit the paradigm presupposed by the 2HTSM model illustrated in Figure 1. Experiment 1 was designed to test the hypotheses as described above. Experiment 2 was designed to assess whether recognition memory for script-typical and script-atypical information is affected by the presentation form of items preceding the target items during acquisition. As will be outlined below, Experiment 2 allows for further tests of the AEH and the SCTH.

\section{EXPERIMENT 1}

\section{Method}

Participants. Forty-four female and male students of Bonn University served as voluntary participants. About $40 \%$ of them were undergraduate psychology majors who received credit toward their degree requirements as compensation for their participation. The other participants were dormitory residents with various majors.

Design and Materials. A story describing a day in the life of Peter W. (a fictitious student) was displayed one sentence at a time on a 14-in. screen of a personal computer. The story consisted of 108 German sentences. Each of these sentences described two actions or events in two semi-sentences connected by the word and (e.g., "Er steht auf und putzt sich die Zähne" [He gets up in the morning and brushes his teeth]). The whole story covered nine different scripts: getting up in the morning, visiting a dentist, attending a lecture, buying pants, repairing the inner tube of a bike, writing a text on a personal computer, painting the walls of a room, visiting a restaurant, and visiting a movie theater (see the Appendix). Vaterrodt (1992) obtained German typicality norms for these scripts. She used a 6-point rating scale analogous to that of Graesser et al. (1979). For each of the nine scripts, 20 actions with the highest and 4 actions with the lowest average typicality ratings were selected for the subsequent source monitoring test. Thus, the test. comprised $9 \cdot(20+4)=216$ actions in total.

The Peter W. story presented to each participant was based on one of two subsets (henceforth referred to as Set A and Set B) of all 216 actions. Two of the actions ranked $!$ to 4 on the typicality scale ( 1 being the most typical action) were randomly assigned to Set $\mathrm{A}$. The remaining two actions were assigned to Set $\mathrm{B}$. The same was done for actions ranked 5 to 8,9 to 12 , and so on. In this way two parallel sets of 108 actions were obtained. Because each sentence described two actions, 54 sentences of a story contained target items. 
Another 54 filler sentences were added to each story. Their purpose was to introduce the student Peter W. and to link the nine scripts to a homogeneous story.

The 36 Set A actions with highest typicality ratings and the 18 Set $A$ actions with lowest typicality ratings were randomly divided into two sets of equal size (Sets $A_{1}$ and $A_{2}$, with 18 typical and 9 atypical items each). The same was done with respect to Set $B$ actions. resulting in Sets $B$, and $B_{2}$, comprising 18 typical and 9 atypical items each. Only these four subsets of items will be considered in the data analyses reported in this paper. Their overall average typicality ratings were 5.6 for the 72 typical and 1.9 for the 36 atypi$\mathrm{cal}$ items. The remaining 54 Set $\mathrm{A}$ actions (Set $\mathrm{A}_{3}$ ) and the corresponding 54 Set $\mathrm{B}$ actions ( $\mathrm{Set} \mathrm{B}_{3}$ ) with medium typicality ratings appeared in the source monitoring test and in the Peter W. stories in order to guarantee a plausible story that was neither too boring (because of a large number of highly typical events) nor too bizarre (because of a large number of atypical events). However, because our hypotheses do not refer to actions of medium typicality, these items were omitted from the data analyses.

To control for possible material effects associated with the four item subsets, $A_{1}, A_{2}, B_{1}$, and $B_{2}$, the total sample of participants was randomly divided into four groups with $n=11$ each. The Peter W. story was based on Set A actions in Groups 1 and 2 and on Set $B$ actions in Groups 3 and 4 . Group 1 received Set $A_{1}$ items in fragmentary form and Set $A_{2}$ items in complete form. For Group 2, the assignment of sets to presentation forms was reversed. Additionally, both Group 1 and Group 2 participants read Set $A_{3}$ items in complete form. In much the same way, participants in Group 3 received Set $B_{1}$ items in fragmentary form and Set $B_{2}$ items in complete form, whereas the assignment of sets to presentation forms was reversed in Group 4. Set $B_{3}$ items were presented in complete form to the participants of both groups.

The fragmentary form of presentation was always limited to the verbs. Fragmented items were pretested to verify that participants could identify the missing letters within $8 \mathrm{sec}$. Because the same source monitoring test was used in all groups, Set A items were target items in Groups 1 and 2 and distractor items in Groups 3 and 4. In contrast, Set B items were target items in Groups 3 and 4 and distractor items in Groups 1 and 2. Thus, the assignment of item subsets to experimental conditions was completely counterbalanced across the four experimental groups.

In order to allow for a study of recognition and source memory for highly typical actions, the nine items with highest typicality ratings in each of the four sets, $A_{1}, A_{2}, B_{1}$. and $B_{2}$, were analyzed separately from the other nine typical and nine atypical items. The overall mean typicality ratings across the four subsets were 5.9, 5.4, and 1.9 for highly typical, typical, and atypical items, respectively. Mean differences among the item subsets $A_{1}, A_{2}, B_{1}$, and $B_{2}$ were negligible. Because ratings for highly typical items were very close to the utmost typicality value (6.0), one must conceive of these items as elements of the generic scripts. Examples of the highly typical, typical, and atypical actions used in our Peter W. stories are presented in the Appendix.

To summarize, we realized a three-factorial $4 \times 2 \times 3$ design (i.e., assignment of item subsets to groups of participants $\times$ item presentation form $\times$ level of typicality). The first factor was a randomized between-subjects control factor. The other two factors were varied within subjects. Measures of recognition memory, source memory, and response biases as defined by the $2 \operatorname{HTSM}(5)$ model served as dependent variables.

Procedure. The participants were told that the experiment was about person perception. They were tested individually. Each participant was asked to read the Peter W. story aloud (including the 27 completed verbs presented in fragmentary form) and to think about what kind of person Peter W. could be. Each of the 108 sentences was presented for $8 \mathrm{sec}$ in the center of the screen. Subsequently, participants were asked to read a comic book that was not related to the
Peter W. story. About 10 min later they were instructed to give a short summary of the content of the comic book. Then a list of person attributes was presented and the participants' task was to assign each of the attributes to either Peter W. or Jolly, the protagonist of the comic book. Exactly $30 \mathrm{~min}$ were reserved for the entire distractor task (comic book reading, summary, and person attribute judgments). The experiment ended with an unexpected source monitoring test. Two hundred and sixteen short sentences describing Set A and Set B actions were presented in a story-conform order. All items were presented in complete form, using the same wording as in the Peter W. stories. The participants had to classify each item as old, old $_{\mathrm{f}}$, or new by pressing one of three keys on the computer keyboard. The participants were informed that their judgments should pertain to the actions depicted in the short sentences and not to the words used to describe them. In total, the experiment lasted between 50 and $65 \mathrm{~min}$.

\section{Results}

For each of the four groups of participants who received different item sets, raw frequencies of old $_{\mathrm{f}}$, old $d_{\mathrm{c}}$, and new responses were calculated for nine item classes (fragmented items, complete items, and distractor items crossed with three levels of typicality). Preliminary data analyses indicated only minor differences among the four groups. Thus, for clarity of presentation, we will refer to the total data set for all $N=44$ participants combined. ${ }^{2}$

Raw and relative frequencies for the total sample are displayed in Table 1. We will first report the goodness of fit of different submodels of the 2HTSM model family. Next we will consider parameter estimates obtained within the framework of the best-fitting 2HTSM submodel. All model-based statistical analyses reported in this paper were conducted by means of the MBT program $(\mathrm{Hu}, 1991$; see Hu \& Batchelder, 1994).

Goodness-of-fit tests. The goodness of fit of different submodels of the 2HTSM model family was evaluated by means of the $\log$-likelihood ratio statistic $G^{2}$, which is asymptotically $\chi^{2}$ distributed if the submodel holds true (Read \& Cressie, 1988). Small values of $G^{2}$ indicate good fit, whereas large values indicate bad fit. All of the following $G^{2}$ tests that were conducted separately for each typicality level are based on $d f=1$ and 1,584

Table 1

Raw and Relative Frequencies of Source Monitoring Responses to Fragmented, Complete, and New Items in Experiment 1, Separately for Highly Typical, Typical, and Atypical Items

\begin{tabular}{|c|c|c|c|c|c|c|}
\hline \multirow[b]{3}{*}{ Target Item } & \multicolumn{6}{|c|}{ Response } \\
\hline & \multicolumn{2}{|c|}{$\operatorname{Old}_{\mathrm{f}}$} & \multicolumn{2}{|c|}{ old $_{\mathrm{c}}$} & \multicolumn{2}{|c|}{$\mathrm{New}$} \\
\hline & Raw & Relative & Raw & Relative & Raw & Relative \\
\hline \multicolumn{7}{|l|}{ Highly typical } \\
\hline Fragmented & 163 & .41 & 161 & .41 & 72 & .18 \\
\hline Complete & 21 & .05 & 253 & .64 & 122 & .31 \\
\hline New & 49 & .06 & 345 & .44 & 398 & .50 \\
\hline \multicolumn{7}{|l|}{ Typical } \\
\hline Fragmented & 139 & .35 & 163 & .41 & 94 & .24 \\
\hline Complete & 39 & .10 & 228 & .58 & 129 & .33 \\
\hline New & 49 & .06 & 266 & .34 & 477 & .60 \\
\hline \multicolumn{7}{|l|}{ Atypical } \\
\hline Fragmented & 213 & .54 & 134 & .34 & 49 & .12 \\
\hline Complete & 20 & .05 & 281 & .71 & 95 & .24 \\
\hline New & 1 & .00 & 26 & .03 & 765 & .97 \\
\hline
\end{tabular}


observations, whereas tests referring to all levels simultaneously are based on $d f=2$ and 4,752 observations. Because we were not interested in detecting tiny deviations from the models ( $w<.1$, see J. Cohen, 1988, chap. 7), we determined that a reasonable level of significance is $\alpha=.0001$ for both types of tests [corresponding to critical values $\chi^{2}(d f=1, \alpha=.0001)=15.137$ and $\chi^{2}(d f=2$, $\alpha=.0001)=18.421$ ]. In the case of $d f=1$ and 1,584 observations, the power amounts to $1-\beta=.536$ for small deviations from the model $(w=.1)$, and it is greater than .999 for moderate deviations $(w=.2)$. For $d f=2$ and 4,752 observations, the power is even larger $(1-\beta=$ .997 for $w=.1$ and $1-\beta>.999$ for $w=.2$ ). Obviously, conventional levels of significance would be inappropriate because they would imply high rates of model rejections even for negligible deviations from the models being tested. ${ }^{3}$

As predicted by both the AEH and the different SCTH versions, the five-parameter 2HTSM(5) model fits the data for highly typical $\left(G_{1}^{2}=1.192\right)$, typical $\left(G_{(1)}^{2}=0.967\right)$, and atypical items $\left(G_{(1)}^{2}=2.986\right)$ almost perfectly. However, as indicated by $G^{2}$ difference tests comparing the 2HTSM(4) and 2HTSM(5) models, the null hypothesis of equal recognition rates for fragmented and complete items $\left(\mathrm{H}_{0}: D_{\mathrm{f}}=D_{\mathrm{c}}\right)$ must be rejected for highly typical $\left(G_{(1)}^{2}=20.697\right)$ and atypical items $\left(G_{(1)}^{2}=18.376\right)$ but not for typical items $\left(G_{(1)}^{2}=9.680\right)$. This result clearly contradicts the narrow version of the $\mathrm{SCTH}$, which predicts a null effect of missing-letters completion on recognition memory for highly typical items.

Parameter estimates. To test the AEH against the extended version of the SCTH, the pattern of parameter estimates obtained within the framework of the $2 \operatorname{HTSM}(5)$ model needs to be examined. The maximum likelihood method of parameter estimation based on the EM algo- rithm described by Hu and Batchelder (1994) was used throughout. Figure 2 illustrates estimates of the recognition rates $D_{\mathrm{f}}$ and $D_{\mathrm{c}}$ together with $95 \%$ confidence intervals. As suggested by the nonoverlapping confidence intervals, the null hypothesis of no typicality effect must be rejected for both fragmented $\left(G_{(2)}^{2}=81.217\right)$ and complete $\left(G_{(2)}^{2}=232.960\right)$ items. Nevertheless, it appears that the typicality effect is stronger for complete items than for fragmented items (Figure 2). However, although the descriptive pattern of parameter estimates is roughly in agreement with the AEH predictions, unequivocal statistical evidence in favor of the AEH is lacking.

As predicted by the SCTH and shown in Table 2, response bias in favor of the old response increases with script typicality. The null hypothesis of no typicality effect in response bias $b$ clearly must be rejected $\left(G_{(2)}^{2}=\right.$ 152.272). In contrast, the null hypotheses of no typicality effects in source memory $d\left(G_{(2)}^{2}=3.231\right)$ and in source bias $g\left(G_{(2)}^{2}=7.390\right)$ can be retained. The maximum likelihood estimate of $d$ for all item types combined was 0.58 [95\% confidence interval: $(.54, .62)$ ], and the corresponding estimate of $g$ was 0.14 [95\% confidence interval: $(.12, .15)]$

\section{Discussion}

Obviously, recognition memory for highly script-typical items can be enhanced substantially by presenting information in fragmentary form. This result clearly contradicts the narrow version of the SCTH. By contrast, both the extended version of SCTH and the AEH can account for this result. Unfortunately, it is not perfectly clear from the data whether the size of the typicality effect is unaffected by the item presentation form, as predicted by the extended SCTH, or reduced for fragmented items, as predicted by the AEH. However, the fact that memory for

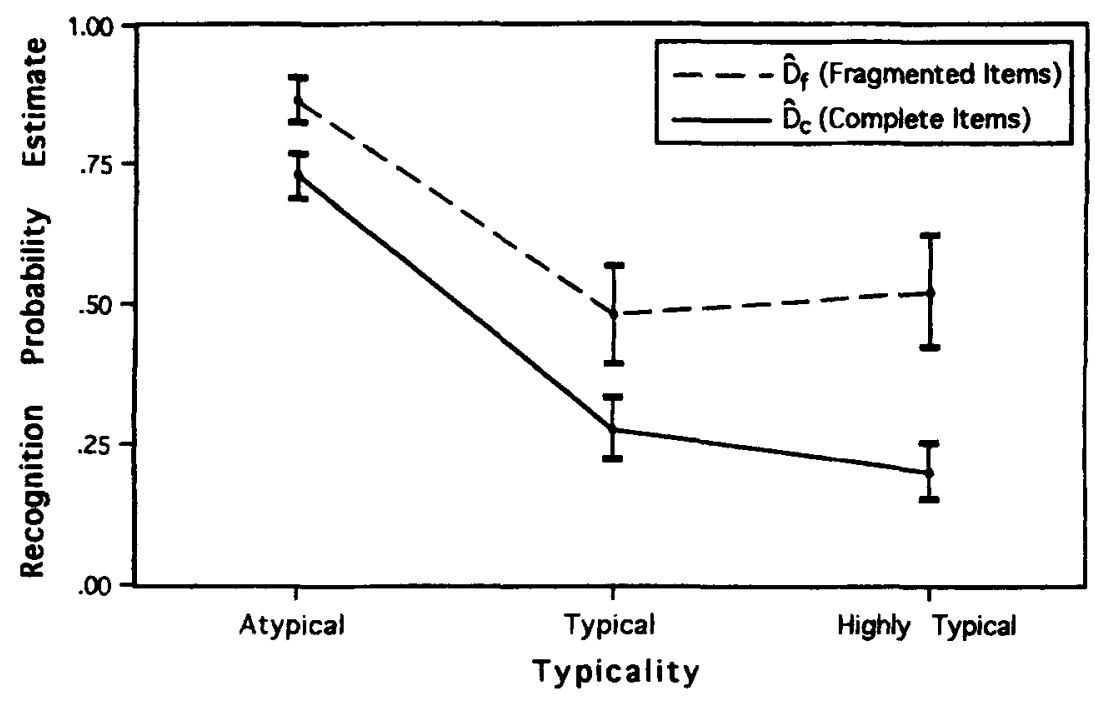

Figure 2. Estimates of the recognition parameters $D_{\mathrm{f}}$ and $D_{\mathrm{c}}$ and $95 \%$ confidence intervals for atypical, typical, and highly typical items originally presented in complete versus fragmentary form (Experiment 1). 
Table 2

Parameter Estimates (PE) and 95\% Confidence Intervals (CI)

According to the 2HTSM(5) Model (Experiment 1)

\begin{tabular}{|c|c|c|c|c|c|c|c|c|c|c|}
\hline \multirow[b]{3}{*}{ Action Type } & \multicolumn{10}{|c|}{ Maximum Likelihood Parameter Estimates } \\
\hline & \multicolumn{2}{|r|}{$D_{\mathrm{f}}$} & \multicolumn{2}{|c|}{$D_{\mathrm{c}}=D_{\mathrm{n}}$} & \multicolumn{2}{|c|}{$b$} & \multicolumn{2}{|c|}{$d$} & \multicolumn{2}{|r|}{$g$} \\
\hline & $\mathrm{PE}$ & $\mathrm{Cl}$ & PE & $\mathrm{CI}$ & PE & $\mathrm{Cl}$ & PE & $\mathrm{Cl}$ & $\mathrm{PE}$ & $\mathrm{CI}$ \\
\hline Highly typical & .518 & $.423-613$ & .199 & $.151-.247$ & .619 & $.587-.652$ & .696 & $.565-.827$ & .114 & $.093-.135$ \\
\hline Typical & .479 & $.394-.564$ & .273 & $.225-.321$ & .548 & $.514-.582$ & .552 . & $.436-.668$ & .169 & $.143-.196$ \\
\hline Atypical & .859 & $.827-.890$ & .726 & $.689-.763$ & .125 & $.087-.162$ & .564 & $.515-.614$ & .128 & $.087-.168$ \\
\hline
\end{tabular}

the form of item presentation was clearly less than perfect for all item types is easier to reconcile with the AEH: According to the extended SCTH, source memory should be almost perfect for both recognized fragmented and recognized complete items because the presence versus absence of an extra tag indicates how this item was displayed originally.

It should be noted that this pattern of results does not depend on whether the data of the four counterbalanced groups are analyzed separately (not reported here) or combined. Moreover, we found a similar pattern of results in data analyses on the basis of the original 1HTSM model by Batchelder and Riefer (1990). Thus, our conclusions do not depend on choosing the 2HTSM(5) model or on other methodological details of the data analyses. This is an important aspect of our results because submodels of different source monitoring model families often show numerically identical goodness of fit, indicating that goodness-of-fit tests may not be informative in selecting the best model (Erdfelder, Murnane, \& Bayen, 1995). Although we would like to reiterate that the 2HTSM(5) model is the optimal source monitoring model for the purposes of the present experiments, we would also like to point out that our substantive conclusions do not depend on the selection of this particular model.

Our model-based results make sense not only with respect to the core parameters $D$ (supposed to measure item recognition memory) and $d$ (supposed to measure source memory), but also with respect to the response bias parameters $b$ (probability of guessing old) and $g$ (probability of guessing old $_{\mathrm{f}}$ given an old decision). As predicted by the SCTH, $b$ increases monotonically with item typicality. In contrast, $g$ does not vary between different levels of typicality. The overall $g$ estimate of 0.14 is easily explained: The participants probably noticed that only very few of the items had originally been displayed in fragmentary form. When they had to guess whether an item classified as old was a fragmented or a complete item originally, it was reasonable for them to choose the latter alternative more frequently. Actually, only 27 items were presented in fragmentary form originally. Their proportion is conspicuously close to the $g$ estimate, perhaps an instance of the well-known phenomenon of probability learning in twochoice situations (Estes, 1964; Jones, 1971).

To summarize, the results of Experiment 1 tend to favor the AEH explanation of the typicality effect, but they do not rule out the extended version of the SCTH. More data are needed to resolve this issue. We therefore designed a second experiment whose primary goal was to obtain clearer evidence in favor or against one of the two hypotheses.

\section{EXPERIMENT 2}

According to the AEH, the degree of elaborative itemspecific processing should not depend only on a target item's content or presentation form but also on other factors that affect the attentional resources devoted to this item. Among these factors is the nature of items preceding the target item in the acquisition phase. Basically, preceding items may affect resource allocation to subsequent target items in different ways, depending on the timing of item presentation during acquisition. If preceding and target items are presented simultaneously for a short time interval or successively and with a very high pace, then attention-attracting preceding items probably decrease attention to subsequent target items: Obviously, given that there is only a limited amount of time to process both items, the time spent with one item is at the expense of the time remaining for processing the other. However, if items are presented successively and in a moderate pace, there is no tradeoff between processing the first item and the second item. Quite to the contrary, one would expect that attention-arousing preceding items "activate" the reader and thus increase the attentional resources available for processing the subsequent target item. This does not automatically result in deeper elaborative processing of this item, though. However, if the subsequent item is salient or difficult to comprehend (e.g., because of its atypical form or content), the increase in available attentional resources is likely to go along with intense itemspecific processing

In deriving the AEH predictions for Experiment 1, we hypothesized that the recognition memory benefit of fragmented items varies as a function of (1) script typicality and (2) the attentional resources devoted to the lettercompletion task. If this holds true, and if attentional resources are indeed affected by the nature of preceding items, it should be possible to increase or decrease the missing-letters effect for each level of typicality by manipulating the effort required for processing the preceding items. This can be achieved, for instance, by contrast- 
ing different item presentation forms (i.e., fragmented vs. complete) in sentences displayed prior to the sentence containing the target information.

In Experiment 1, the presentation form of preceding items varied nonsystematically and was not controlled. According to the AEH, therefore, the overall missingletters effects for highly typical, typical, and atypical items must be regarded as mixtures of different effect sizes for different types of preceding items. In Experiment 2 , we aimed at separating the components of these mixtures. In particular, we tested whether it is possible to obtain (1) large missing-letters effects by analyzing target items preceded by sentences containing fragmented verbs and (2) small missing-letters effects by analyzing target items preceded by sentences without fragmented verbs. To obtain such effects it is of course necessary to ensure that the processing of the preceding information does not reduce the time available for processing the target items. This can best be achieved by choosing sufficiently long time lags between preceding and target information.

According to the $\mathrm{AEH}$, large missing-letters effects should coincide with a small typicality effect for fragmented items because typical items will benefit more from missing-letter completion than atypical items (see above). Thus, a very small or even nonexistent typicality effect should emerge when both target item and preceding item are presented in fragmentary form. In contrast, the typicality effect should be much stronger when target and preceding items are presented in complete form.

These predictions cannot be derived from either version of the SCTH discussed so far. As noted, the SCTH predicts that the size of the typicality effect should remain invariant against changes of the encoding context (see Graesser \& Nakamura, 1982). Thus, features of items preceding the target items during acquisition should neither diminish nor boost the typicality effect as predicted by the AEH.

Experiment 2 was designed to test the AEH and SCTH predictions concerning context effects of items preceding the target information during acquisition.

\section{Method}

Participants. Forty female and male students of Bonn University served as voluntary participants. All of them were undergraduate psychology majors who received credit toward their degree requirements as compensation for their participation.

Design and Materials. The Peter W. stories constructed for Experiment 1 could not be reused because the presentation form of items preceding the target items was not controlled in these stories. Therefore, new Peter W. stories were constructed. ${ }^{4}$ They are based on eight of the nine scripts referred to in Experiment 1; the script "writing a text on a personal computer" was not used in Experiment 2. Moreover, we decided to drop the distinction between highly typical and typical items because differences were generally small in Experiment 1.

For each of the eight scripts, the 12 most typical and the 4 least typical actions were selected from the norms obtained by Vaterrodt (1992). Both the most and the least typical items were subdivided into four parallel sets, $A_{1}, A_{2}, B_{1}$, and $B_{2}$, in much the same way as done in Experiment 1 . The overall mean typicality ratings were 5.8 for typical and 1.9 for atypical actions. Differences between parallel item subsets were negligible.

Half of the participants received Set A items as target items and Set $B$ items as distractor items in the source monitoring test. The other half received Set B items as targets and Set A items as distractors. Each half was again subdivided into two groups of equal size. One group received Subset $A_{1}$ (or $B_{1}$ ) in fragmentary form and Subset $A_{2}$ (or $B_{2}$ ) in complete form. For the other groups the order was reversed.

Each participant read one of the four versions of the Peter W. story on a 14-in. screen of a personal computer. Presentation conditions and context conditions were almost identical to those of Experiment 1 . The stories consisted of 104 German sentences similar to those used in Experiment 1. Each target item was preceded by a sentence ending with a highly script-typical action that was presented in either fragmentary form or complete form ( $50 \%$ each). Eight seconds later, a new sentence starting with the critical target item replaced the preceding sentence. There were four types of target items: highly typical and fragmented, highly typical and complete, atypical and fragmented, and atypical and complete ( $25 \%$ each).

The source monitoring test presented subsequently covered 160 items. Of these, 32 were critical target items originally presented in the Peter W. story (4 items for each combination of the factors presentation form of the target item, typicality of the target item, and presentation form of the preceding item). Another 32 (parallel) test items served as distractor items. Thus, each participant contributed 64 responses to the data analyses reported below.

To summarize, we realized a four-factorial $4 \times 2 \times 2 \times 2$ design (i.e., assignment of item subsets to groups of participants $\times$ target item presentation form $\times$ target item typicality $\times$ presentation form of preceding item). The first factor was a randomized betweensubjects control factor. The other three factors were varied within subjects. Measures of recognition memory, source memory, and response biases as defined by the 2 HTSM(5) model served as dependent variables.

Procedure. The procedure was identical to that of Experiment 1. Experiment 2 took 55-65 min for each participant.

Table 3

Raw and Relative Frequencies of Source Monitoring Responses to Fragmented, Complete, and New Items in Experiment 2, Separately for Highly Typical and Atypical Items Preceded by Fragmented Versus Complete Items

\begin{tabular}{|c|c|c|c|c|c|c|}
\hline \multirow[b]{3}{*}{ Target Item } & \multicolumn{6}{|c|}{ Response } \\
\hline & & Dld $d_{\mathrm{f}}$ & & $\int d_{\mathrm{c}}$ & & New \\
\hline & Raw & Relative & Raw & Relative & Raw & Relative \\
\hline
\end{tabular}

Target Items Preceded by Fragmented Items

Highly typical

Fragmented

Complete

101

18

$.63 \quad 48$

$48 \quad .30$

New

47

.15

103

.30

$.32 \quad 170$

11

Atypical

Fragmented

Complete

New

110

$.69 \quad 45$

8
3

.05

45
127

.28

.79

$.02 \quad 312$

$\begin{array}{r}25 \\ 312 \\ \hline\end{array}$

Target Items Preceded by Complete Items

Highly typical

$\begin{array}{lllllll}\text { Fragmented } & 72 & 45 & 60 & 38 & 28 & 18\end{array}$

$\begin{array}{lrrrrrr}\text { Complete } & 21 & .13 & 113 & .71 & 28 & .16\end{array}$

$\begin{array}{lllllll}\text { New } & 31 & .10 & 108 & .34 & 181 & .57\end{array}$

Atypical

$\begin{array}{lllllll}\text { Fragmented } & 115 & .72 & 33 & .21 & 12 & .08\end{array}$

$\begin{array}{lrrrrrr}\text { Complete } & 11 & .07 & 126 & .79 & 23 & .14\end{array}$

$\begin{array}{lllllll}\text { New } & 2 & .01 & 11 & .03 & 307 & .96\end{array}$




\section{Results}

For each of the four groups of participants who received different item sets, raw frequencies of old $_{\mathrm{f}}$, old ${ }_{\mathrm{c}}$, and new responses were calculated for 12 item classes (i.e., fragmented items, complete items, and distractor items crossed with two levels of typicality and two types of preceding items). A preliminary data analysis indicated that differences between the four groups were negligible. Thus, for clarity of presentation, we will refer to the total data set for all $(N=40)$ participants combined.

Rav' and relative frequencies for the total sample are displayed in Table 3. Again, we will first report the goodness of fit of different submodels of the 2HTSM model family. Next we will consider parameter estimates ob- tained within the framework of the best-fitting 2 HTSM submodel.

Goodness-of-fit tests. $G^{2}$ goodness-of-fit tests were conducted for each combination of target item typicality and type of preceding item separately and for several of these four item groups combined. Power considerations were similar to those reported for Experiment 1. If "moderate" or large effects are of interest ( $\mathbf{w}>.2$, see note 2$)$, a significance level of $\alpha=.0001$ is again a good choice for tests that refer to several groups of items. Given $d f=$ 1 , two item groups ( 1,280 observations $)$, and the critical value $\chi^{2}(d f=1, \alpha=.0001)=15.137$, the power of the $G^{2}$ test is $\mathrm{I}-\beta=.377$ for $\mathbf{w}=.1$, and it is greater than .999 for $\mathbf{w}=.2$. For tests based on $d f=3$, four item
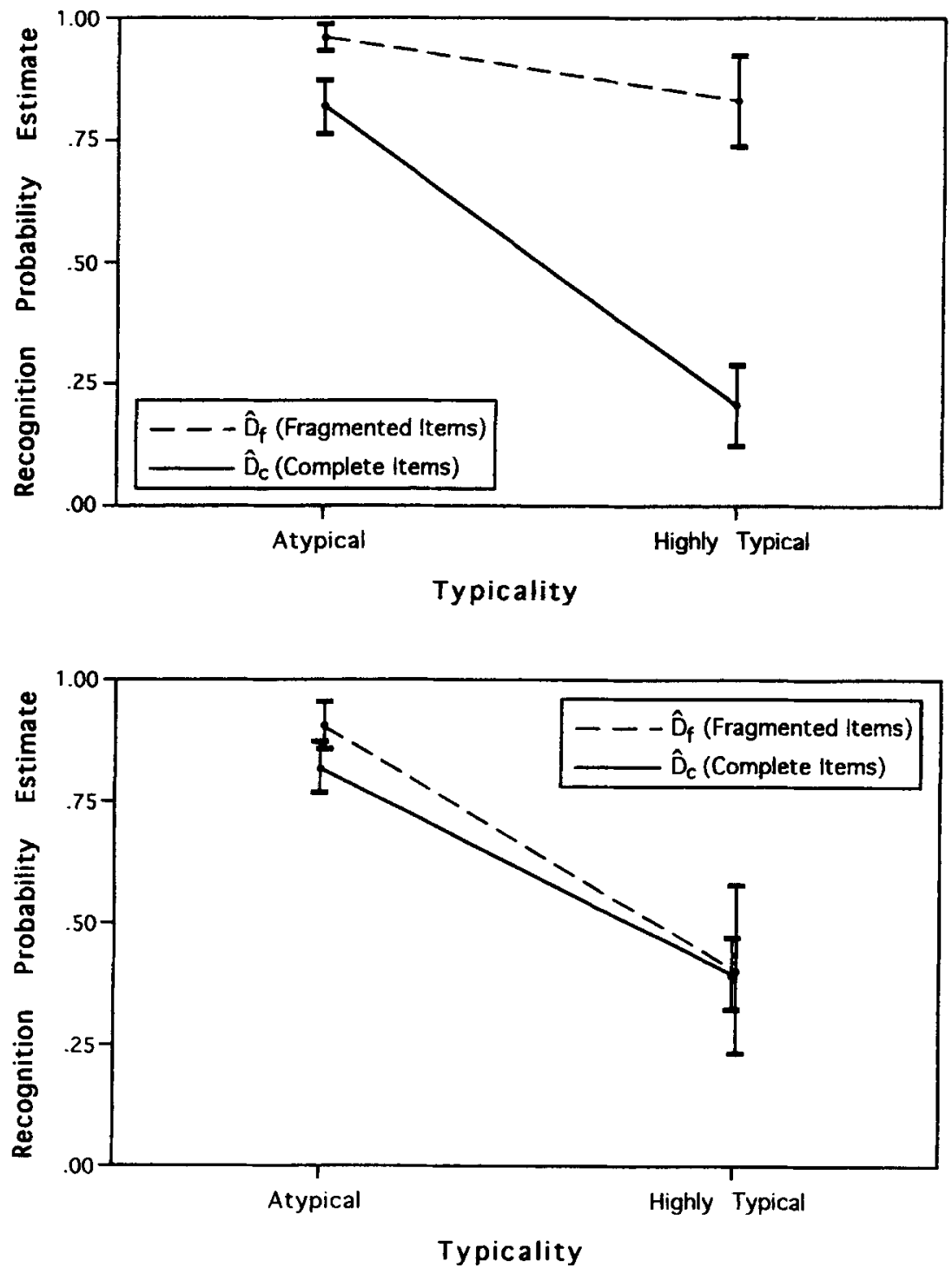

Figure 3. Estimates of the recognition parameters $D_{\mathrm{f}}$ and $D_{\mathrm{c}}$ and $95 \%$ confidence intervals for atypical and highly typical items originally presented in complete versus fragmentary form. All target items were preceded by fragmented items (top panel) versus complete items (bottom panel) during the acquisition phase of Experiment 2. 
groups (2,560 observations), and the critical value $\chi^{2}(d f=3, \alpha=.0001)=21.1075$, the power is even larger. However, if single item groups are analyzed (640 observations), $\alpha=.001$ is a better choice. Given $d f=1$, $\mathbf{w}=.2$, and the critical value $\chi^{2}(d f=1, \alpha=.001)=$ 10.828 , the power amounts to $1-\beta=.962$.

The five-parameter 2 HTSM(5) model again fits the data for each of the four groups of items almost perfectly. $G_{(1)}^{2}$ is equal to $2.928,1.753,0.448$, and 0.615 for highly typical items preceded by fragmented items, atypical items preceded by fragmented items, highly typical items preceded by complete items, and atypical items preceded by complete items, respectively. As in Experiment 1, the null hypothesis of equal recognition rates for fragmented and complete target items (i.e., $\mathrm{H}_{0}: D_{\mathrm{f}}=D_{\mathrm{c}}$ ) and, thus, the four-parameter $2 \mathrm{HTSM}(4)$ model, cannot be retained for both highly typical $\left(G_{(1)}^{2}=38.063\right)$ and atypical $\left(G_{(1)}^{2}=15.806\right)$ items that were preceded by fragmented items. In contrast, for target items preceded by complete items, the null hypothesis $D_{\mathrm{f}}=D_{\mathrm{c}}$ can be retained for both highly typical items $\left(G_{(1)}^{2}=0.009\right)$ and atypical items $\left(G_{(1)}^{2}=4.074\right)$.

Parameter estimates. Figure 3 illustrates estimates of the recognition rates $D_{\mathrm{f}}$ and $D_{\mathrm{c}}$ and $95 \%$ confidence intervals. Using $\alpha=.0001$ as a criterion of significance (see above), the null hypothesis of no typicality effect can be retained for fragmented items preceded by other fragmented items $\left(G_{(1)}^{2}=9.078\right)$ but must be rejected for complete items preceded by fragmented items $\left(G_{(1)}^{2}=\right.$ $118.019)$. By contrast, for target items preceded by complete items, there is a sizable typicality effect for both fragmented $\left(G_{(1)}^{2}=30.950\right)$ and complete target $\left(G_{(1)}^{2}=\right.$ 66.070) items.

Table 4 summarizes the results for the remaining parameters. Again, response bias in favor of the old response increases with script typicality. The null hypothesis of no typicality effect in response bias $b$ must be rejected for items preceded by fragmented items $\left(G_{(1)}^{2}=33.934\right)$ and for items preceded by complete items $\left(G_{(1)}^{2}=36.611\right)$. In contrast, the source memory and source bias parameters are affected neither by item typicality nor by the type of the preceding item: $\left(G_{(3)}^{2}=2.455\right.$ for parameter $d$ and $G_{(3)}^{2}=2.468$ for parameter $g$ ). The maximum likelihood estimate of $d$ for all groups of items combined is $0.68[95 \%$ confidence interval: $(.63, .72)]$, and the cor- responding estimate of $g$ is 0.25 [ $95 \%$ confidence interval: $(.21, .28)]$

\section{Discussion}

Two important results were observed in Experiment 2. First, missing-letters effects can be strengthened considerably by combining fragmented target items with fragmented preceding items, and they can be weakened by combining fragmented target items with less attentionarousing preceding items presented in complete form. Second, for fragmented target items preceded by other fragmented items, the typicality effect is virtually eliminated or at least reduced to a negligible size. Thus, if participants are strongly encouraged to attend to and to thoroughly process highly typical information, recognition rates may be as large as those usually obtained for atypical information only (see also Alba \& Hasher, 1983).

These results corroborate the AEH predictions. The AEH can readily explain why (1) there is a sizable effect of the preceding items' presentation form and why (2) the typicality effect disappears (or almost disappears) when both atypical and highly typical items are processed elaboratively. The extended version of the SCTH can account for the latter result only by assuming that a ceiling effect prevents the fragmented atypical items from being recognized significantly better than the fragmented highly typical items. However, even if this interpretation should turn out to be correct, the SCTH still cannot account for the effect of the preceding item's presentation form. The SCTH versions considered in this article do not provide for context-sensitive tagging mechanisms. Tags should therefore remain unaffected by the presentation form of items preceding or following the target items.

Moreover, there is pretty much agreement between the $D_{\mathrm{f}}$ estimates obtained in Experiments 1 and 2. To see this, the $D_{\mathrm{f}}$ estimates for targets preceded by fragmented items versus complete items in Experiment 2 have to be weighted with the proportions of fragmented and complete items in the stories used in Experiment 1 (.125 and .875 , respectively). The sums of these weighted estimates (i.e., their weighted averages) roughly coincide with the $D_{\mathrm{f}}$ estimates observed in Experiment 1. This confirms our supposition that the missing-letters effects obtained in Experiment 1 are in fact mixtures of different effect sizes for different types of preceding items.

Table 4

Parameter Estimates (PE) and 95\% Confidence Intervals (CI) According to the 2HTSM(5) Model (Experiment 2), Separately for Items Preceded by Fragmented Versus Complete Items

\begin{tabular}{|c|c|c|c|c|c|c|c|c|c|c|}
\hline \multirow[b]{3}{*}{ Action Type } & \multicolumn{10}{|c|}{ Maximum Likelihood Parameter Estimates } \\
\hline & \multicolumn{2}{|r|}{$D_{\mathrm{f}}$} & \multicolumn{2}{|c|}{$D_{\mathrm{c}}=D_{\mathrm{n}}$} & \multicolumn{2}{|c|}{$b$} & \multicolumn{2}{|c|}{$d$} & \multicolumn{2}{|r|}{$g$} \\
\hline & $\mathrm{PE}$ & $\mathrm{CI}$ & $\mathrm{PE}$ & $\mathrm{CI}$ & $\mathrm{PE}$ & $\mathrm{CI}$ & PE & $\mathrm{Cl}$ & PE & $\mathrm{CI}$ \\
\hline \multicolumn{11}{|c|}{ Target Items Preceded by Fragmented Items } \\
\hline Highly typical & .831 & $.748-.915$ & .209 & $.134-.282$ & .585 & $.534-.635$ & .630 & $.523-.737$ & .276 & $.228-.324$ \\
\hline Atypical & .964 & $.937-.990$ & .819 & $.770-.868$ & 137 & $.060-.214$ & .653 & $.583-.723$ & .190 & $.109-.271$ \\
\hline \multicolumn{11}{|c|}{ Target Items Preceded by Complete Items } \\
\hline Highly typical & .406 & $.239-.572$ & .395 & $.331-.459$ & .718 & $.663-.774$ & .812 & $.514-1.00$ & .236 & $.187-.285$ \\
\hline Atypical & .904 & $.859-.949$ & .815 & $.766-.864$ & .221 & $.127-.315$ & .719 & $.649-.790$ & .233 & $.143-.322$ \\
\hline
\end{tabular}


There is one unexpected result in Experiment 2, though: The missing-letters effects seem to vanish almost completely for targets preceded by complete items. Although reduced missing-letters effects were predicted by the $\mathrm{AEH}$, zero effects are not easily explained by both the $\mathrm{AEH}$ and the extended SCTH. However, the nonsignificance of an effect does not imply its complete absence. In fact, small effects in the predicted direction show up in the parameter estimates. One possible reason for these tiny effects is the rather low difficulty level of the letter-completion task used in our experiments. It was perhaps not difficult enough to induce intense item-specific processing in the absence of attention-arousing context influences.

With respect to the parameters $b, d$, and $g$, the results of Experiment 2 are also similar to those already observed in Experiment 1. As predicted by the $\mathrm{SCTH}$, response bias toward the old response (b) increases with item typicality. The other parameters are constant across item types. Source memory $d$ appears to be slightly better than in Experiment 1 but is still less than perfect. This is not easily reconciled with the SCTH but is consistent with the AEH. Finally, the estimate of the source bias parameter $g$ is again close to the proportion of items that were presented in fragmentary form originally. This confirms our suspicion that probability learning may play a role in the guessing processes underlying source bias.

\section{GENERAL DISCUSSION}

We have conducted two experiments to test three explanations of the typicality effect: the AEH, a narrow version of the SCTH, and an extended version of the SCTH. Experiment 1 showed that presenting information in fragmentary form tends to improve recognition memory mostly for highly typical information. This is inconsistent with the narrow version of the SCTH. Measures of recognition memory and source memory fitted the AEH predictions quite well but did not clearly rule out the extended version of the SCTH. Experiment 2 revealed that features of items preceding the target item during acquisition may affect the size of the typicality effect in recognition memory. Neither the narrow nor the extended version of the SCTH can account for this context effect. By contrast, the AEH predicts this effect.

In a nutshell, our data support the AEH and pose some problems for the SCTH. This converges with recent resuits of other authors based on different SCTH and AEH predictions. For example, O'Sullivan and Durso (1984) and Hunt, Kernan, and Bonfield (1992) have shown that atypical information is not only easily remembered but also improves recognition and recall memory for other pieces of information in the same text, both typical and atypical. Thus, memory for script-related information appears to be affected by features of items preceding the target item and also by features of items following the target item during acquisition (see also Graesser, Singer, \& Trabasso, 1994, p. 379). This can hardly be explained by item-specific or proposition-specific tags. The AEH, however, is in agreement with this result: Elaborative processes triggered by atypical information tend to improve associative links to other (perhaps highly typical) information in the same story and thereby improve its retrievability (see Hastie, 1980).

In a study on memory for typical and atypical objects in real-world settings, Mäntylä and Bäckman (1992) showed that the typicality effect may disappear in recognition memory for object details. This null effect was found both in elderly people and in young adults working under divided-attention conditions. Obviously, these results do not fit the SCTH assumption that atypical information is tagged automatically and without involvement of attentional processes. However, they are easily explained within the AEH framework: Whenever the attentional resources are exhausted (due to limited attentional capacities of the participants or due to features of the experimental context), atypical information ceases to be processed elaboratively. As a consequence, atypical items lose their memory advantage relative to typical items. Similar results were reported with respect to memory for typical and atypical person and group attributes encoded under conditions of divided attention (Macrae, Hewstone, \& Griffiths, 1993; Stangor \& Duan, 1991).

Another core assumption of the SCTH pertains to the interaction between item typicality, type of memory test (i.e., recall versus recognition), and the delay of the memory test. According to Graesser and Nakamura (1982), a general atypicality advantage should be found only in immediate memory tests of either type. With increasing retention intervals, recall memory should become more reconstructive and less recollective, resulting in better recall memory for (highly) typical information relative to atypical information. The typicality effect in recognition memory, by contrast, should not depend on the length of the retention interval because recognition memory is generally less reconstructive than recall memory. In accordance with these predictions, Smith and Graesser (1981) found an atypicality advantage in recognition memory for all retention intervals, whereas the atypicality advantage in recall memory was limited to short retention intervals and reversed into a typicality advantage approximately $48 \mathrm{~h}$ after testing. Recently, however, Davidson (1994) demonstrated that the reversal of the typicality effect in recall memory is limited to atypical items describing relatively pallid and routine actions. Atypical items reflecting highly attention-attracting interruptive actions, by contrast, were generally recalled and recognized better than typical items of the same type, regardless of the length of the retention interval.

To summarize, recent evidence-including our ownclearly emphasizes the importance of attentional and elaborative processes in memory for schema-related and script-related information. Nevertheless, the data do not force a complete rejection of the SCTH in favor of the $\mathrm{AEH}$; some other results not discussed until now are predicted by the SCTH but not easily explained within the AEH framework. 
First, as summarized by Graesser and Nakamura (1982, pp. 94-95), some manipulations of attentional resources failed to affect the typicality effect. For example, the typicality effect appears to be unaffected by speed of presentation rates [medium ( 175 words $/ \mathrm{min}$.) vs. fast ( 280 words/min.)] of script-based stories (see, however, Dijksterhuis \& van Knippenberg, 1995), and the typicality effect seems largely invariant under different instructions (telling the participants to place more or less emphasis on typical vs. atypical actions).

Second, the AEH provides no simple explanation of the often-observed correlation between typicality and response bias in favor of the old response that was replicated in our experiments.

Third, there is some evidence confirming the SCTH prediction that at least some script-typical items have no representation in memory at all. Subsets of highly typical items can be defined for which recognition memory is essentially zero (Bredenkamp \& Vaterrodt, 1992; Graesser \& Nakamura, 1982; Grube-Unglaub et al., 1995; Vaterrodt, 1992). According to the SCTH, these items have no representation in memory beyond the copy of the script. As a consequence, there should be no implicit memory for these items, either. Using different types of indirect measures of memory, this prediction was indeed confirmed by Bredenkamp and Vaterrodt (1992) and GrubeUnglaub et al. (1995). A pure version of the AEH can hardly explain these results because it implies that all types of information should receive low degrees of attention and elaborative processing at least, leading to recognition rates generally larger than zero.

Thus, neither the SCTH nor the AEH is in perfect agreement with all results reported in the literature. As far as the SCTH is concerned, the problems seem to be due to the fact that this theory explicitly denies the importance of attentional and elaborative processes in producing the typicality effect: "According to the SC+T model, there can be systematic differences in attention and elaboration devoted to items, but such differences do not explain the typicality effect. Instead, properties of the representational code can explain the typicality effect, and the code is constructed automatically at comprehension" (Graesser \& Nakamura, 1982, p. 94). Note that the problems would disappear within the framework of a revised SCTH that retains the script-copy framework but rejects the idea that attentional and elaborative processes are not involved in tagging mechanisms. By assuming that memory representations of script-based stories include script copies established automatically and, additionally, traces or tags corresponding to items receiving item-specific elaborative processing during encoding (because of their atypicality or other reasons), most of the results mentioned in this paper are captured (see McDaniel, 1984, and McDaniel \& Kerwin, 1987, for a similar point of view). In accordance with the original SCTH, the revised SCTH predicts zero memory for highly typical information that does not receive item-specific processing, it predicts good memory for atypical information that does receive item-specific elaborative processing, and it predicts an increase in response bias with increasing item typicality. In contrast to the original $\mathrm{SCTH}$, however, the revised SCTH predicts good memory for highly typical information that does receive elaborative item-specific processing (e.g., because of its form of presentation or because of its atypical context; see Hunt et al., 1992; O'Sullivan \& Durso, 1984). Note also that the revised SCTH does not assume automatic tagging mechanisms, so it can easily explain Mäntylä and Bäckman's (1992) results. Furthermore, it predicts recall and recognition advantages for all types of information processed elaboratively, regardless of the length of the retention interval. Thus, as was recently found by Davidson (1994), attention-attracting atypical information should be generally recognized and recalled better at all retention intervals.

Although the results of our experiments are nicely explained by the $\mathrm{AEH}$, the revised $\mathrm{SCTH}$ is an attractive alternative. It can also explain some results of other authors that do not fit well into the AEH framework. In addition, the revised SCTH includes most of the AEH predictions. It differs from the AEH only with respect to memory factors and judgment strategies involved in remembering aspects of the generic script (i.e., highly script-typical items). Thus, the revised SCTH is a combination of the successful parts of the AEH and the SCTH, and one might therefore call it a revised AEH as well.

Still another but related way to account for our results in a revised SCTH framework was suggested by Arthur Graesser (personal communication, April 1, 1997). In line with contemporary models in discourse psychology, one could argue that several levels of memory representation are constructed during text comprehension-for example, a surface model (i.e., a verbatim representation), a text base (i.e., a propositional representation), and a situation model describing the situation referred to in the text (see Kintsch, 1988; Kintsch \& Ericsson, 1996; Kintsch et al., 1990). Given such a framework, the SCTH would not be in conflict with the data reported here when we assume that it applies to the construction of the situation model only. The observed missing-letters effects and their interactions with typicality and type of the preceding item could then be explained by referring to the other levels of memory representation. In other words, attentional and elaborative processes may be involved in the encoding of script-based texts according to this revised SCTH. However, such processes operate primarily at the surface level rather than the situation model level, where script copies plus tags for atypical events are stored. Note that some degree of attention appears to be necessary to store tags for atypical events, though. Otherwise it would be difficult to explain why the recognition memory benefit of atypical events tends to vanish under conditions of divided attention.

For the time being, therefore, a definite decision between the AEH framework and the SCTH framework seems neither possible nor desirable. What can be said is that SCTH versions denying the role of attentional and elaborative processes in memory for script-typical and 
script-atypical information cannot account for some recent data, including our own. However, by dropping the SCTH assumption that attentional and elaborative processes do not affect the typicality effect, the inconsistency between the $\mathrm{AEH}$ and the SCTH can be resolved.

\section{REFERENCES}

Adams, L. T., \& Worden, P. E. (1986). Script development and memory organization in preschool and elementary school children. Discourse Processes, 9, 149-166.

Alba, J. W., \& Hasher, L. (1983). Is memory schematic? Psychological Bulletin, 93, 203-231.

Batchelder, W. H., Hu, X., \& Riefer, D. M. (1994). Analysis of a model for source monitoring. In G. H. Fischer \& D. Laming (Eds.), Contributions to mathematical psychology, psychometrics, and methodology (pp. 51-65). New York: Springer-Verlag.

BATCHELDER, W. H., \& RiEFER, D. M. (1990). Multinomial models of source monitoring. Psychological Review, 97, 548-642.

Batchelder, W. H., RiefER, D. M., \& Hu, X. (1994). Measuring memory factors in source monitoring: Reply to Kinchla. Psychological Review, 101, 172-176.

Bayen, U. J., Murnane, K., \& Erdfelder, E. (1996). Source discrimination, item detection, and multinomial models of source monitoring. Journal of Experimental Psychology: Learning, Memory, \& Cognition, 22, 197-215.

BellezZA, F. S., \& Bower, G. H. (1981). The representational and processing characteristics of scripts. Bulletin of the Psychonomic Society, 18, 1-4.

BLAXTON, T. A. (1989). Investigating dissociations among memory measures: Support for a transfer-appropriate processing framework Journal of Experimental Psychology: Learning, Memory, \& Cognition, 15, 657-668.

Bobrow, D. G., \& Norman, D. A. (1975). Some principles of memory schemata. In D. G. Bobrow \& A. Collins (Eds.), Representation and understanding (pp. 131-149). New York: Academic Press.

BOWER, G. H., BLACK, J. B., \& TURNER, T. J. (1979). Scripts in memory for text. Cognitive Psychology, 11, 177-220.

BredenKamp, J., \& Vaterrodt, B. (1992). Direkte und indirekte Gedächtnisprüfung skriptbezogener Informationen [Direct and indirect memory tests of script-based information]. Sprache \& Kognition, 11, 14-26.

Brewer, W. F., \& NaKamURA, G. V. (1984). The nature and functions of schemas. In R. S. Wyer \& T. K. Srull (Eds.), Handbook of social cognition (Vol. 1, pp. 119-160). Hillsdale, NJ: Erlbaum.

BREWER, W. F., \& TREYENS, J. C. (1981). Role of schemata in memory for places. Cognitive Psychology, 13, 207-230.

BurNS, D. J. (1990). The generation effect: A test between single and multifactor theories. Journal of Experimental Psychology: Learning. Memory, \& Cognition, 16, 1060-1067.

CANTOR, N., \& MisCHEL, W. (1977). Traits as prototypes: Effects on recognition memory. Journal of Personality \& Social Psychology, 35, 38-48.

Cohen, C. E. (1981). Person categories and social perception: Testing some boundaries of the processing effects of prior knowledge. Journal of Personality \& Social Psychology, 40, 441-452.

COHEN, J. (1988). Statistical power analysis for the behavioral sciences (2nd ed.). Hillsdale, NJ: Erlbaum.

CRAIK, F. I. M., \& LOCKHART, R. S. (1972). Levels of processing: A framework for memory research. Journal of Verbal Learning \& Verbal Behavior, 11, 671-684.

Davidson, D. (1994). Recognition and recall of irrelevant and interruptive atypical actions in script-based stories. Journal of Memory \& Language, 33, 757-775.

Davidson, D., \& HoE, S. (1993). Children's recall and recognition memory for typical and atypical actions in script-based stories. Jour nal of Experimental Child Psychology, 55, 104-126.

Dijksterhuis, A., \& van KNIPPEnberg, A. (1995). Memory for stereotype-consistent and stereotype-inconsistent information as a function of processing pace. European Journal of Social Psychology, $25,689-693$

Einstein, G. O., McDaniel, M. A., Bowers, C. A., \& Stevens, D. T. (1984). Memory for prose: The influence of relational and propositionspecific processing. Journal of Experimental Psychology: Learning. Memory, \& Cognition, 10, 133-143.

Einstein, G. O., McDaniel, M. A., Owen, P. D., \& Coté, N. C. (1990) Encoding and recall of texts: The importance of material appropriate processing. Journal of Memory \& Language, 29, 566-581.

ERDFElder, E., FAul, F., \& Buchner, A. (1996). GPOWER: A general power analysis program. Behavior Research Methods, Instruments, \& Computers, 28, 1-11.

Erdfelder, E., Murnane, K., \& Bayen, U. J. (1995). Die Messung kognitiver Prozesse im Paradigma der Quellendiskrimination [The measurement of cognitive processes in the source monitoring paradigm]. In K. Pawlik (Ed.), Bericht über den 39. Kongreß der Deutschen Gesellschaft für Psychologie in Hamburg (pp. 541-547). Göttingen: Hogrefe.

Estes, W. K. (1964). Probability learning. In A. W. Melton (Ed.), Categories of human learning (89-128). New York: Academic Press.

Fabricius, W. V., Hodge, M. H., \& Quinan, J. R. (1993). Processes of scene recognition memory in young children and adults. Cognitive Development, 8, 343-360.

FAUL, F., \& ERDFELDER, E. (1992). GPOWER: Apriori, post hoc, and compromise power analyses for MS-DOS [Computer program]. Bonn: Psychologisches Institut der Universität Bonn.

FiedLER, K., LACHNIT, H., FAY, D., \& KRUG, C. (1992). Mobilization of cognitive resources and the generation effect. Quarterly Journal of Experimental Psychology, 45A, 149-171.

FriedMAN, A. (1979). Framing pictures: The role of knowledge in automatized encoding and memory for gist. Journal of Experimental Psychology: General, 108, 316-355.

Graesser, A. C., Gordon, S. E., \& SAWyer, J. D. (1979). Recognition memory for typical and atypical actions in scripted activities: Tests of the script pointer + tag hypothesis. Journal of Verbal Learning \& Verbal Behavior, 18, 319-332.

Graesser, A. C., \& Nakamura, G. V. (1982). The impact of a schema on comprehension and memory. In G. H. Bower (Ed.), The psychology of learning and motivation (Vol. 16, pp. 59-109). New York: Academic Press.

Graesser, A. C., Singer, M., \& Trabasso, T. (1994). Constructing inferences during narrative text comprehension. Psychological Review, 101, 371-395.

Graesser, A. C., Woll, S. B., Kowalski, D. J., \& Smith, D. A. (1980). Memory for typical and atypical actions in scripted activities. Journal of Experimental Psychology: Human Learning \& Memory, 6 , 503-515.

GRAF, P. (1982). The memorial consequences of generation and transformation. Journal of Verbal Learning \& Verbal Behavior, 21, 539-548.

Grube-Unglaub, S., Bredenkamp, J., Vaterrodt-PlünNecke, B., \& FISCHER, V. (1995). Indirekte Gedächtnisprüfung skriptbezogener Informationen [Indirect memory tests of script-based information] Zeitschrift für Experimentelle Psychologie, 42, 1-24.

HASTIE, R. (1980). Memory for behavioral information that confirms or contradicts a personality impression. In R. Hastie, T. Ostrom, E. Ebbesen, R. S. Wyer, D. L. Hamilton, \& D. Carlston (Eds.), Person memory: The cognitive basis of social perception (pp. 155-177). Hillsdale, NJ: Erlbaum.

$\mathrm{Hu}, \mathrm{X} .(1991)$. Statistical inference program for multinomial binary tree models: Version 1.0 [Computer program]. Irvine: University of California at Irvine, Department of Mathematical Behavioral Sciences.

Hu, X., \& BATChelder, W. H. (1994). The statistical analysis of general processing tree models with the EM algorithm. Psychometrika, 59, $21-47$.

Hudson, J. A. (1988). Children's memory for atypical actions in scriptbased stories: Evidence for a disruption effect. Journal of Experimental Child Psychology, 46, 159-173.

Hunt, J. M., Kernan, J. B., \& Bonfield, E. H. (1992), Memory structure in the processing of advertising messages: How is unusual information represented? Journal of Psychology, 126, 343-356. 
Johnson, M. K., Hashtroudi, S., \& Lindsay, D. S. (1993). Source monitoring. Psychological Bulletin, 114, 3-28.

JONES, M. R. (1971). From probability learning to sequential processing: A critical review. Psychological Bulletin, 76, 153-185.

KINCHLA, R. A. (1994). Comments on Batchelder and Riefer's multinomial model for source monitoring. Psychological Review, 101, 166-171.

KINTscH, W. (1970). Learning, memory, and conceptual processes. New York: Wiley.

KINTSCH, W. (1988). The role of knowledge in discourse comprehension: A construction-integration model. Psychological Review, 95, 163-182.

KintsCh, W., \& Ericsson, A. (1996). Die kognitive Funktion des Gedächtnisses [The cognitive function of memory]. In D. Albert $\&$ K.-H. Stapf (Eds.), Gedächtnis (Enzyklopädie der Psychologie, C, II, Vol. 4, pp. 541-601). Göttingen: Hogrefe.

Kintsch, W., Welsch, D., Schmal.hofer, F., \& Zimny, S. (1990). Sentence memory: A theoretical analysis. Journal of Memory \& Language, 29, 133-159.

Light, L. L., Kayra-Stuart, F., \& Hollander, S. (1979). Recognition memory for typical and unusual faces. Journal of Experimental Psychology: Human Learning \& Memory, 5, 212-228.

locksley, A., Stangor, C., Hepburn, C., Grosovsky, E., \& HochSTRASSER, M. (1984). The ambiguity of recognition memory tests of schema theories. Cognitive Psychology, 16, 421-448.

Macrae, C. N., Hewstone, M., \& Griffiths, R. J. (1993). Processing load and memory for stereotype-based information. European Journal of Social Psychology, 23, 77-87.

MAKI, R. H. (1990). Memory for script actions: Effects of relevance and detail expectancy. Memory \& Cognition, 18, 5-14.

MANDLER, J. M. (1984). Stories, scripts, and scenes: Aspects of schema theory. Hillsdale, NJ: Erlbaum.

MäNTYLÄ, T., \& BäCKMAN, L. (1992). Aging and memory for expected and unexpected objects in real-world settings. Journal of Experimental Psychology: Learning, Memory, \& Cognition, 18, 1298-1309.

MARKHAM, R., \& LISSNER, D. (1994). The effect of typicality and retention interval on discriminative memory for instruments. Australian Journal of Psychology, 46, 170-176.

MCDANIEL, M. A. (1984). The role of elaborative and schema processes in story memory. Memory \& Cognition, 12, 46-51.

McDaniel, M. A., Einstein, G. O., Dunay, P. K., \& Cobb, R. E. (1986). Encoding difficulty and memory: Toward a unifying theory. Journal of Memory \& Language, 25, 645-656.

MCDANiEl, M. A., \& KeRWIN, M. L. E. (1987). Long-term prose retention: Is an organizational schema sufficient? Discourse Processes, 10, 237-252.

Murnane, K., \& Bayen, U. J. (1996). An evaluation of empirical measures of source identification. Memory \& Cognition, 24, 417-428.

Nakamura, G. V., Graesser, A. C., Zimmerman, J. A., \& Riha, J. (1985). Script processing in a natural situation. Memory \& Cognition, 13, 140-144

O'Sullivan, C. S., \& Durso, F. T. (1984), Effect of schema-incongruent information on memory for stereotypical attributes. Journal of Personality \& Social Psychology, 47, 55-70.

Pezdek, K., Whetstone, T., Reynolds, K., Askari, N., \& DoughERTY, T. (1989). Memory for real-world scenes: The role of consistency with schema expectation. Journal of Experimental Psychology: Learning, Memorv, \& Cognition, 15, 587-595.

READ, T. R. C., \& CREssiE, N. A. C. (1988). Goodness-of-fit statistics for discrete multivariate data. New York: Springer-Verlag.

Riefer, D. M., Hu, X., \& Batchelder, W. H. (1994). Response strategies in source monitoring. Journal of Experimental Psychology: Learning, Memory, \& Cognition, 20, 680-693.

Roediger, H. L., III, WELDON, M. S., \& CHALLIS, B. (1989). Explaining dissociations between implicit and explicit measures of retention: A processing account. In H. L. Roediger III \& F. I. M. Craik (Eds.), Varieties of memory and consciousness: Essay's in honour of Endel Tulving (pp. 4-41). Hillsdale, $\mathrm{NJ}$ : Erlbaum.

SCHANK, R. C., \& ABELSON, R. (1977). Scripts, plans, goals, and under standing. Hillsdale, NJ: Erlbaum.
Schmalhofer, F., \& Glavanov, D. (1986). Three components of understanding a programmer's manual: Verbatim, propositional, and situational representations. Journal of Memory \& Language, 25, 279 294.

SCHMIDT, D. F., \& SHERMAN, R. C. (1984). Memory for persuasive messages: A test of a schema-copy-plus-tag model. Journal of Personatity \& Social Psychology, 47, 17-25.

ScHMIDT, S. R. (1992). Evaluating the role of distinctiveness in the generation effect. Quarterly Journal of Experimental Psychology, 44A, 237-260.

Shapiro, P. N., \& Penrod, S. (1986). Meta-analysis of facial identification studies. Psychological Bulletin, 100, 139-156.

SlameCKa, N, J., \& GRaF, P. (1978). The generation effect: Delineation of a phenomenon. Journal of Experimental Psychology: Human Learning \& Memory, 4, 592-604.

SMITH, D. A., \& GRAESSER, A. C. (1981). Memory for actions in scripted activities as a function of typicality, retention interval, and retrieval task. Memory \& Cognition, 9, 550-559.

STANGOR, C., \& DUAN, C. (1991). Effects of multiple task demands upon memory for information about social groups. Journal of Experimental Social Psychology, 27, 357-378.

Stangor, C., \& McMillan, D. (1992). Memory for expectancycongruent and expectancy-incongruent information: A review of the social and social developmental literatures. Psychological Bulletin, $111,42-61$.

StRACK, F., \& Bless, H. (1994). Memory for non-occurrences: Metacognitive and presuppositional strategies. Journal of Memory \& Lan guage, 33, 203-217.

Thomas, J. P., \& Olzak, L. A. (1992). Simultaneous detection and identification. In F. G. Ashby (Ed.), Multidimensional models of perception and cognition (pp. 253-277). Hillsdale, NJ: Erlbaum.

VATERRODT, B. (1992). Skripts und Gedächtnis [Scripts and memory] Frankfurt: Lang.

Woll, S. B., \& Graesser, A. C. (1982). Memory discrimination for information typical and atypical of person schemata. Social Cognition, $1,287-310$.

YeKoVICH, F. R., \& WALKER, C. H. (1986). Retrieval of scripted knowledge. Journal of Memory \& Language, 25, 627-644.

\section{NOTES}

1. As one reviewer noted, one could develop a version of the SCTH that assumes that each additional tag is proportionally less beneficial for recognition memory. Obviously, it would be more difficult to test this theory against the AEH. However, this theory is not the one proposed by Graesser and Nakamura (1982).

2. Readers may request results for single groups of participants from the first author

3. All power analyses reported in this paper were performed by means of the GPOWER program (Faul \& Erdfelder, 1992; see Erdfelder, Faul, \& Buchner, 1996). They are based on J. Cohen's (1988, chap. 7) effect size measure $\mathbf{w}$, which indicates the degree of violation of the null hy pothesis $\left(\mathrm{H}_{0}\right)$ in the underlying population. For each item type $i$, the de gree of violation is $\mathbf{w}_{i}^{2}=\sum_{j}\left(p_{0 i j}-p_{1 i j}\right)^{2} / p_{0 i j}$, where $p_{1 i j}$ is the actual probability of response $j$ to items of type $i$ in the underlying population and $p_{0 i j}$ is the corresponding probability according to $\mathrm{H}_{0}$ (i.e., the model being tested). In our application, there were three responses $-j=1,2$, $3\left(\right.$ old $_{\mathrm{f}}$, old $\mathrm{c}$, and new). Some of our tests refer to three item types, other tests to even more. The overall degree of $\mathrm{H}_{0}$ violation across item types is $\mathbf{w}^{2}=\sum_{i} n_{i} / N \cdot \mathbf{w}_{i}^{2}$, where $n_{i}$ is the sample size for items of type $i$, and $N$ is the total sample size across item types. Thus, a "small effect" $\mathbf{w}=$ .1 as defined by J. Cohen (1988, p. 224)-implies that the weighted average of the $\mathbf{w}_{i}^{2}$ terms is as tiny as $\mathbf{w}^{2}=.01$. We decided that our tests should detect "moderate" violations of $\mathrm{H}_{0}$ (i.e., $w=.2$ or $\mathbf{w}^{2}=.04$ ) with a high power, but not necessarily small violations. Note that all power calculations refer to asymptotic distributions; they are not necessarily valid for small sample sizes

4. We would like to thank Natascha Braun for constructing the mate rials and collecting the data of Experiment 2. 


\section{APPENDIX}

Table A1

Examples of Highly Typical, Typical, and Atypical Items Used in the Peter W. Stories of Experiments 1 and 2

\begin{tabular}{|c|c|c|c|}
\hline \multirow[b]{2}{*}{ Script } & \multicolumn{3}{|c|}{ Typicality } \\
\hline & Highly typical & Typical & Atypical \\
\hline $\begin{array}{l}\text { morning } \\
\text { dentist } \\
\text { lecture } \\
\text { buying pants } \\
\text { bike } \\
\text { writing a text } \\
\text { painting walls } \\
\text { restaurant } \\
\text { movie }\end{array}$ & $\begin{array}{l}\text { He enters the bathroom. } \\
\text { He opens his mouth. } \\
\text { He looks for a place. } \\
\text { He chooses a pair of pants. } \\
\text { He inflates the tires. } \\
\text { He saves the text. } \\
\text { He paints the wall with a roller. } \\
\text { They eat. } \\
\text { They buy tickets. }\end{array}$ & $\begin{array}{l}\text { He combs his hair. } \\
\text { He describes his pains. } \\
\text { He takes his pen. } \\
\text { He tries on another one. } \\
\text { He marks the puncture. } \\
\text { He defines the print format. } \\
\text { He cleans the roller. } \\
\text { They drink something. } \\
\text { They look at the posters. }\end{array}$ & $\begin{array}{l}\text { He drinks champagne. } \\
\text { He takes an aspirin. } \\
\text { He eats chocolate. } \\
\text { He haggles over the price. } \\
\text { He stitches the rip. } \\
\text { He inserts a battery. } \\
\text { The bucket drops down. } \\
\text { They buy cigarettes. } \\
\text { Peter falls asleep. }\end{array}$ \\
\hline
\end{tabular}

(Manuscript received October 17, 1996;

revision accepted for publication July 16, 1997.) 